\title{
Processing and sensory properties of high-fibre bakery products Deepshikha Kataria $^{1}$, Shubhangi Dalmia ${ }^{2}$
}

Department of Food \& Nutrition, Institute of Home Economics (University of Delhi), Hauz Khas, New Delhi-16

\begin{abstract}
The present study was conducted to improve the nutritional composition of cakes and biscuits which are generally made with refined flour. Refined wheat flour was substituted with Germinated Sorghum Flour and Plantain Flour. Process parameters such as height, diameter, spread ratio and spread factor were recorded for biscuits. For cakes, process parameters such as batter $\mathrm{pH}$, acidity, density, baking temperature and cake volume were assessed. Weight of biscuits increased from $8.05 \mathrm{~g}$ in control to $9.27 \mathrm{~g}$ in variation made with germinated sorghum and plantain. There was significant reduction $(p<0.05)$ in spread ratio of biscuits with increased amount of germinated sorghum and plantain flours. The spread ratio reduced from 7.63 (control) to 6.68 indicating less spread of biscuits during baking. In conclusion, substitution of refined wheat flour with germinated sorghum and plantain provides dual benefits of improving nutritional quality of the baked products and also it improves process parameters which are essential for scale-up during commercial production of biscuits and cakes.
\end{abstract}

Keywords—Bakery products, germinated sorghum flour, plantain, high fibre, cakes, biscuits.

\section{INTRODUCTION}

Fibre is an important dietary component that has several beneficial roles in our body. Various studies have proved that there is a relationship between the lack of fiber in the diet and the incidence of several common diseases [1]. The diseases commonly associated with low-fiber diets include coronary heart disease, diabetes mellitus, diverticular disease, colon cancer, appendicitis, and dental caries. In today's changing world, consumer's preference of taste has led to refinement of flours to make bakery products with improved textural properties and taste. Consequently, the fiber content of diets has also reduced. Substitution of refined flours with whole grains has potential to improve the nutritional value and fiber content of the food products. Whole grains and millets such as sorghum, ragi etc. can be used as a substitute of refined flours. Sorghum and plantain (Green banana) are rich sources of Resistant Starch (RS) and can be used in many products to increase their fiber content.

Sorghum: Sorghum is also known as jowar in India, belongs to the tribe Andropogonae of the grass family Poaceae. It is a gluten-free cereal and can also be used for celiac patients [2]. It is rich in phytochemicals, phenolics, sterols, and anthocyanins [3]. It also provides minerals such as magnesium, copper, manganese, iron and zinc and vitamins such as thiamin, riboflavin, niacin, vitamin B-6 and pantothenate [4]. Sorghum can be used to make different kinds of food products. Products like bread and cookies have been made with sorghum bran incorporated up to 15 and $30 \%$ without any significant differences in texture or flavor profiles compared to whole wheat products [5]. Other examples include porridges [6], germinated malt products, which include porridges and some alcoholic and non-alcoholic beverages, like Mahewu, which is produced in Zimbabwe [7]. The germinated sorghum flour can be used in preparation of bread, muffins, biscuits etc. Another well-established use of sorghum is in production of leavened baked goods such as wheat-sorghum composite bread [8].

Plantain: Plantain (Green banana) is a traditional product which can be dried to form flour and can be used to substitute refined flours. It is a good source of carbohydrates and dietary fiber [9]. Plantain contains higher hemicelluloses content $(6.08 \%)$ than most fruits and vegetables. Apart from dietary fiber, it is also good source of some essential minerals such as potassium, and various vitamins (A, B1, B2 and C) [10]. It also has high nutraceutical potential [11]. Plantain powder or flour has been used widely as an ingredient in the food industries [12]. Many research works have proved that consumption of plantain is beneficial to human health due to its resistant starch (RS) content [13].

Health benefits of Resistant starch (RS): "Resistant starch has been defined as the fraction of starch, which escapes digestion in the small intestine but is digested in the large intestine after 5 to 7 hours of consumption" [14]. Fermentable fiber and RS are associated with improved glucose tolerance. There is evidence that this is caused by the presence of the short chain fatty acids (SCFA) and by a peptide produced in the fermentation process [15]. Resistant starch (RS) has been proved to be beneficial for digestive health as it increases stool bulk, acts as a mild laxative, promotes the growth of healthy bacteria in the gut [16] and reduces $\mathrm{pH}$ in the intestine. SCFA also reduces the risk of ulcerative colitis and colon cancer by promoting the lipid and cholesterol metabolism [17]. RS also help in the management of diabetes by reducing the glycemic index of food 
[18], [19]. RS does not cause sensory changes in food products [20]. It provides better appearance; texture and mouth- feel than conventional fibers to food products [21].

\section{MATERIAL AND METHOD}

\subsection{Selection and procurement of raw materials}

The study comprised of development of two types of bakery products. For biscuit preparation, refined wheat flour, plantain flour, germinated sorghum flour, sugar, butter, baking powder and milk were used. All above-mentioned ingredients were also used in preparation of cakes along with eggs.

\subsection{Preparation of Plantain Flour (PF)}

PF was prepared according to the method given by [22]. The plantain was peeled and sliced into thin slices of 2-3 $\mathrm{cm}$ each. These slices were washed to remove stickiness. Washed slices were dried at room temperature for moisture evaporation and then dried in a dehydrator at $55^{\circ} \mathrm{C}$ for 3 days. The dehydrated banana slices were grounded in a mixer to form the flour.

\subsection{Preparation of Germinated Sorghum Flour (GSF)}

GSF was prepared using method given by [23]. Sorghum grains were steeped in distilled water at room temperature overnight. 1-2 $\mathrm{ml}$ of $0.2 \%$ formaldehyde solution was added for $40 \mathrm{~min}$ to retard mold growth during germination. The grains were washed 4-5 times and soaked for 20 minutes in distilled water to remove formaldehyde. Washed grains were spread on jute a bag saturated with distilled water and allowed to germinate for 5 days at room temperature. After germination, the grains were dried in dehydrator at $60{ }^{\circ} \mathrm{C}$ for fiber days and grounded to a fine powder.

\subsection{Development of bakery products (cakes \& biscuits) using Plantain Flour (PF) \& Germinated Sorghum Flour (GSF)}

Cakes and biscuits were selected to substitute Refined Wheat Flour (RWF) with GSF \& PF. Equal ratios of GSF \& PF (1:1) were mixed to form a flour mix. This flour mix of GSF \& PF was used to substitute RWF to prepare biscuits and cakes. Five variations of biscuits and cakes were prepared by substituting the RWF with a flour mix. The variations used in product development are given in Table 1. Short dough biscuits and cream cakes were prepared using the basic recipe.

TABLE 1

COMBINATIONS OF FLOURS USED FOR DEVELOPMENT OF BAKERY PRODUCTS

\begin{tabular}{|c|c|c|}
\hline Variations & Refined Wheat Flour (RWF) & Plantain \& Germinated Sorghum Flour (1:1) (GSF + PF) \\
\hline Code 1 (control) & 100 & 0 \\
\hline Code 2 & 60 & 40 \\
\hline Code 3 & 40 & 60 \\
\hline Code 4 & 20 & 80 \\
\hline Code 5 & 0 & 100 \\
\hline
\end{tabular}

\subsection{Process parameters for biscuits}

Weight, Height, diameter, spread ratio and baking time and the temperature was done as process parameters for biscuits.

1.5.1 Weight: The weight of the baked biscuit was determined by weighing 6 biscuits on a weighing balance and calculating mean weight.

1.5.2 Height: The height was measured before and after baking. The thickness of biscuits was determined by placing six biscuits on top of one another. The total height was recorded in millimeters with the help of a ruler. This process was repeated thrice to get an average value and results were reported in $\mathrm{mm}$ [24].

1.5.3 Diameter: The diameter was measured before and after baking. The diameter of biscuits six biscuits was determined by placing six biscuits edge to edge. The total diameter of the six biscuits was measured in $\mathrm{mm}$ by using a ruler. The biscuits were rotated at an angle of $90^{\circ}$ for duplicate reading. The process was repeated twice and average diameter was reported in millimetre [24]. 
1.5.4 Spread ratio: Three rows of five well-formed biscuits were made and the height measured. Also the same was arranged horizontally edge to edge and sum diameter measured [25]. Spread ratio of a cookie is the diameter divided by its thickness. Spread ratio and spread factor were calculated using the following equation:

Formula used

$$
\begin{gathered}
\text { Spread Ratio }=\frac{\text { Diameter }}{\text { Height }} \\
\text { Spread factor }=\frac{\text { Spread ratio of sample }}{\text { Spread ratio of control }} \times 100
\end{gathered}
$$

\subsection{Process parameters for cakes}

The process parameters of cakes include estimation of batter $\mathrm{pH}$, batter density, batter acidity, baking time, baking temperature and cake volume.

1.6.1 Batter pH: The $\mathrm{pH}$ meter was standardized using standard buffer solution at $25{ }^{0} \mathrm{C}$. The sample was taken in a beaker and $\mathrm{pH}$ was measured by a digital $\mathrm{pH}$ meter [26].

1.6.2 Batter density: Batter density was determined as the ratio of the weight of a standard container filled with batter to that of the same container filled with water.

1.6.3 Batter acidity: The acidity of the cake batter was measured by taking $5 \mathrm{gm}$ of batter in a beaker. The batter was mixed with $10 \mathrm{ml}$ of water and titrated against $0.1 \mathrm{~N} \mathrm{NaOH}$ using phenolphthalein as indicator.

1.6.4 Baking time: Baking time was measured using a digital watch. Baking time was measured as the time required for cakes to turn golden brown in the oven during baking.

1.6.5 Baking temperature: It is measured using a calibrated laboratory thermometer.

1.6.6 Cake volume: Cake volume was measured with a calibrated ruler. The volume was calculated using following by dividing height of the batter with final height of the cake after baking.

\subsection{Sensory evaluation of biscuits and cakes}

Sensory evaluation of bakery products (biscuits and cakes) was conducted with a panel of 30 members comprising of students and faculty members. The products were analyzed for appearance, Color, Taste, Texture, Aftertaste and each parameter was rated on a score of 25 and compared to control.

\section{RESUlts AND DISCUSSION}

The use of plantain and sorghum has been well established in the past as a gluten-free alternative to wheat. In the present study, Plantain Flour (PF) and Germinated Sorghum Flour (GSF) were used to substitute Refined Wheat Flour (RWF) in preparation of bakery products (cakes and biscuits). The yield obtained for Plantain Flour (PF) was $64.7 \%$ and $94.5 \%$ for Germinated Sorghum Flour (GSF). Five variations of cakes and biscuits were developed using five different ratios of Refined Wheat Flour (RWF), GSF and PF (Table 1). Germinated Sorghum Flour (GSF) and Plantain Flour (PF) were mixed in equal ratios and this flour mix was used to replace Refined Wheat Flour (RWF) in preparation of biscuits and cakes. Process parameters were recorded for biscuits and cakes to ascertain changes occurring as a result of incorporating high-fiber flour mix.

\subsection{Process parameters of biscuits}

The weight of the biscuits increased from $8.05 \mathrm{~g}$ in code 1 to $9.27 \mathrm{~g}$ in code 5 indicating that there is increase in weight of the biscuits with increased incorporation of GSF and PF. The differences in the weight of biscuits could be due to increased fiber content. Mean diameter of the biscuits) prepared from different ratios of flours containing RWF, GSF \& PF varied significantly $(p<0.05)$ between the variations and control (Table 2). It was observed that diameter of the biscuits was decreasing with higher ratios of GSF \& PF. The diameter of code 5 was $54.90 \mathrm{~mm}$ which was prepared with GSF \& PF whereas significantly high diameter was observed in code $1(56.5 \mathrm{~mm})$ which was made up of RWF only. Incorporation of GSF and PF improved the binding properties of biscuits and prevents spread during baking. The height of the biscuits was affected positively with increase in the amount of Germinated Sorghum Flour (GSF) and Plantain Flour (PF). A gradual increase was observed in the height of the biscuits as the level of GSF and PF were increased and RWF was reduced. The 
height noted in code 1 was $7.2 \mathrm{~mm}$ and $8.4 \mathrm{~mm}$ in code 5 . The height of the biscuits was affected positively as there was an increase in the height of the biscuits by increasing levels of Moth bean Flour supplementation [27]. The height of biscuits measured in millimetres, signifies the increase in thickness of biscuits after baking due to expansion. More height of biscuits could be due to higher amounts of crude fiber and crude protein incorporated in the biscuits with higher ratios of GSF and PF. The height of the biscuits also affects spread ratio of biscuits. Spread ratio or diameter of cookies has been used to determine the quality of flour for producing cookies [28]. Flour and sugar are the main hydrophilic components in cookies that influence biscuit spread. Hydrophilic starches have a negative relation with spread ratio of cookies. During baking, hydrophilic starch granules absorbed moisture and become swollen and gelatinized, thus providing the additional viscosity in cookies [29]. Gluten and fiber present in flours are hydrophilic in nature which retains water and increases viscosity. The hydrophilic compound in GSF and PF are starch \& fiber which are present in high amounts. It increases viscosity resulting in a decrease in spread ratio. The spread ratio of biscuits decreased from 7.63 in control to 6.68 in code 5 . Spread factor is the ratio that depends on the values of the thickness and diameter of the biscuits. In the present study, the spread factor of biscuits gradually decreases as the amount of GSF and PF increases. The spread factor of biscuits decreased from100 in control biscuits to 87.54 in code 5 (Table 2).

\section{TABLE 2}

PROCESS PARAMETERS OF ALL VARIATIONS OF BISCUITS

\begin{tabular}{|c|c|c|c|c|}
\hline Variations & Weight $(\mathbf{g})$ & Diameter $(\mathbf{m m})$ & Height $(\mathbf{m m})$ & Spread Ratio \\
\hline Code1(Control) & 8.05 & $56.50^{\mathrm{a}}$ & $7.20^{\mathrm{a}}$ & $7.63^{\mathrm{a}}$ \\
\hline Code 2 & 8.24 & $56.70^{\mathrm{bc}}$ & $7.40^{\mathrm{ab}}$ & $7.47^{\mathrm{ab}}$ \\
\hline Code 3 & 8.29 & 56.10 & $7.40^{\mathrm{ab}}$ & $6.95^{\mathrm{ab}}$ \\
\hline Code 4 & 9.06 & $55.30^{\mathrm{c}}$ & $8.20^{\mathrm{ab}}$ & $6.80^{\mathrm{ab}}$ \\
\hline Code 5 & 9.27 & $54.90^{\mathrm{ab}}$ & $8.40^{\mathrm{ab}}$ & $6.68^{\mathrm{ab}}$ \\
\hline
\end{tabular}

*All values within column having same superscripts are significantly different $(p<0.05)$

\subsection{Baking Time $\&$ Temperature of biscuits}

Baking time and temperature of biscuits were measured for all the five variations. Time was measured using a stopwatch and measured till the biscuits turned golden brown. The temperature was measured using a calibrated lab thermometer. It was observed that with increased incorporation of GSF and PF, there is decrease in baking time of biscuits but the baking temperature remains the same (Table 3).There is a decrease in baking time from 20 minutes in code 1 to 15 minutes in code 5. The baking temperature of all variations of biscuits was same i.e. $175{ }^{\circ} \mathrm{C}$ (Table 3). The decrease in time of baking with higher levels of Germinated Sorghum Flour (GSF) and Plantain Flour (PF) could be attributed to the slightly darker color of these flours as compared to Refined Wheat Flour (RWF). The darker color of these two flours gives golden brown color to the biscuits in less time as compared to RWF biscuits.

TABLE 3

BAKING TIME \& TEMPERATURE OF BISCUITS

\begin{tabular}{|c|c|c|}
\hline Variation & Baking temperature & Baking time \\
\hline Code1(Control) & $175^{\circ} \mathrm{C}$ & 20 mins \\
\hline Code 2 & $175^{\circ} \mathrm{C}$ & $18 \mathrm{mins}$ \\
\hline Code 3 & $175^{\circ} \mathrm{C}$ & $16 \mathrm{mins}$ \\
\hline Code 4 & $175^{\circ} \mathrm{C}$ & $16 \mathrm{mins}$ \\
\hline Code 5 & $175^{\circ} \mathrm{C}$ & $15 \mathrm{mins}$ \\
\hline
\end{tabular}

\subsection{Process Parameters for Cakes}

The results obtained are presented in Table 4 and 5. A decrease in $\mathrm{pH}$ and increased titratable acidity was noted in cake batters as GSF and PF were increased. The specific volume of baked cake indicates the amount of air that can remain in the final product. A higher gas retention and higher expansion of the product leads to a higher specific volume [30]. After baking, the specific volumes of cake with incorporation of flours were determined and a significantly higher value with increasing GSF and PF indicates a more volume of air retained in the cakes. Cake batters containing GSF and PF with lower batter density (code 5, Table 4) exhibited higher gas retention and resulting in a higher specific volume (2.8), due to the expansion of gas retained in the batter. As the amount of GSF and PF are increased in the batter formulation, the density of 
batter decreases from 1.09in code 1 to 1.0 in code 5 (Table 4). With the increased incorporation of GSF and PF, there was a decrease in baking time from 20 minutes in code 1 to 15 minutes in code 5 (Table 5) but the baking temperature remains the same $\left(185^{\circ} \mathrm{C}\right.$ for all variations).

TABLE 4

Process PARAMETERS FOR VARIATIONS OF CAKE

\begin{tabular}{|c|c|c|c|c|}
\hline Variations & Batter density & Batter $\mathbf{~ H ~}$ & Batter Acidity $(\%)$ & Cake volume $\mathbf{( c m}^{\mathbf{3})}$ \\
\hline Code1 (Control) & 1.09 & 7 & 0.35 & $2.0^{\mathrm{ab}}$ \\
\hline Code 2 & 1.087 & 7.2 & 0.3 & $2.55^{\mathrm{ab}}$ \\
\hline Code 3 & 1.076 & 7.12 & 0.24 & $2.5^{\mathrm{ab}}$ \\
\hline Code 4 & 1.04 & 7 & 0.13 & $2.41^{\mathrm{ab}}$ \\
\hline Code 5 & 1 & 6.8 & 0.07 & $2.8^{\mathrm{ab}}$ \\
\hline
\end{tabular}

*Mean values in a column having different alphabets are significantly different from control $(P<0.05)$.

TABLE 5

BAKING TIME \& TEMPERATURE OF VARIATIONS OF CAKE

\begin{tabular}{|c|c|c|}
\hline Variation & Baking temperature & Baking time \\
\hline Code1(Control) & $185^{\circ} \mathrm{C}$ & 20 mins \\
\hline Code 2 & $185^{\circ} \mathrm{C}$ & 18 mins \\
\hline Code 3 & $185^{\circ} \mathrm{C}$ & 16 mins \\
\hline Code 4 & $185^{\circ} \mathrm{C}$ & 15 mins \\
\hline Code 5 & $185^{\circ} \mathrm{C}$ & \\
\hline
\end{tabular}

\subsection{Sensory Evaluation of biscuits and cakes}

Sensory evaluation of cakes and biscuits was performed by a panel of 30 members comprising of faculty members and students of Institute of Home Economics. Panelists analyzed the product for appearance, color, taste, texture, aftertaste and overall acceptability of the product. All parameters were rated on a score sheet of 100 marks where each attribute was given 25 marks. The results of sensory evaluation of biscuits are represented in Fig. 1. The results reveal that taste (22.4), flavor (22.63) and texture (22.51) of code 2 is very high as compared to code 1 (control) and other variations. Hence it can be concluded that the sensory properties of variations (code 2 - code 5) were comparable to the control (code 1) and variations were equally acceptable. Therefore, substitution of RWF with fiber-rich components such as GSF and PF was found suitable for bakery products and biscuits can be prepared with acceptable sensory qualities. Five variations of cakes were prepared using refined wheat flour (RWF), Germinated Sorghum Flour (GSF) \& Plantain Flour (PF). The control sample (code 1) was prepared using RWF. Other 4 variations were prepared using different ratios of RWF; GSF \& PF were mixed to prepare cakes rich in fiber. GSF \& PF were mixed in equal ratios (1:1) for substituting RWF. The results exhibit that taste (21.96), flavor (21.73) and texture (21.76) of code 2 is comparable with the taste (22.73), flavor (22.16) and texture (22.06) of code 1. The code 5 (22.33) was highly acceptable in terms of flavor as compared to control and other variations (Fig. 2). Substitution of RWF with conventional sources of fiber such as GSF and PF is suitable and bakery products and cakes can be made with acceptable sensory qualities.

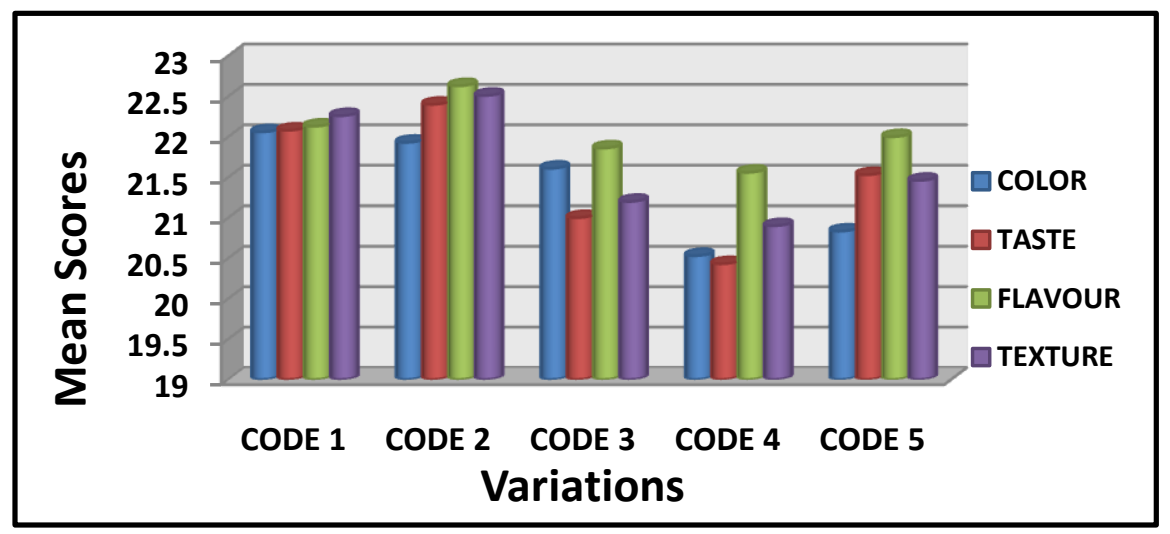

FIG. 1: SENSORY EVALUATION OF BISCUITS 


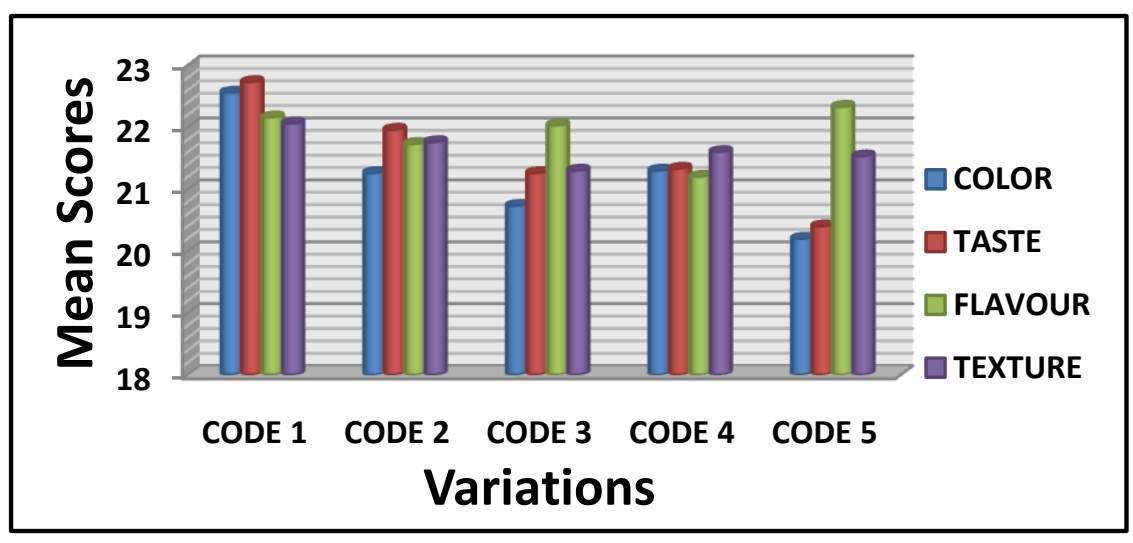

FIG. 2: SENSORY EVALUATION OF CAKES

\section{CONCLUSION}

In conclusion, the biscuits and cakes can be made with non-traditional ingredients without affecting the sensory properties of these products. Germinated sorghum and plantain are low cost ingredients and can be used to replace refined flours. These flours can also be used for people who suffer from gluten intolerance and need to substitute their diet with gluten free flours. Resistant starch present in plantain can improve gastrointestinal health and have positive effect of gut microflora. The base material used for preparation of biscuit and cake is refined wheat flour which is low in fiber. Refined Wheat Flour can be replaced by fiber rich materials such as plantain flour and germinated sorghum flour. This will lead to the development of more nutritious products like bakery products (cakes \& biscuits). Incorporation of plantain flour \& germinated Sorghum flour in equal ratios (1:1) is useful as it increases fiber content, protein and minerals like calcium, phosphorus etc. in the baked goods. Refinement of flours has led to a reduction in fiber content of our diets. It is important to address the issue and target improvement of products where refined wheat flour is a major ingredient.

\section{REFERENCES}

[1] T. L. Raymond, W. E. Connor, D. S. Lin, S. Warner, M. M. Fry, S. L. Connor, "The interaction of dietary fibres and cholesterol upon the plasma lipids and lipoproteins, sterol balance and bowel function in human subjects," J. Clin. Invest., 1977, vol. 60, PP. $142-143$.

[2] C. L. Ciacci, N. N. Maiuri, C. Caporaso, L. Bucci, Del Giudice, D.R. Massardo, P. Pontieri, N. Di Fonzo, S.R. Bean, B. Ioerger, M. Londei, "Celiac disease: In vitro and in vivo safety and palatability of wheat-free sorghum food products," Clinical Nutrition, 2007, vol. 26, pp. 799-805.

[3] Awika, J. M., and Rooney, L. W. Sorghum phytochemicals and their potential impact on human health. Phytochem. 2004, vol. 65, pp. 1199-1221.

[4] USDA, "National Nutrient Database for Standard Reference," Release 24, 2011.

[5] C. M. Mitre-Dieste, L. A. Gordon, J. Awika, E. L. Suhendro, L.W. Rooney, "Cookies made with sorghum brans high in phenols and catechins," Phytochemistry, 2000, vol. 62 (9), pp. 1199-1221.

[6] J. Taylor and J. R. N. Taylor, "Alleviation of the adverse effect of cooking on sorghum protein digestibility through fermentation in traditional African porridges," International Journal of Food Science and Technology, 2002, vol. 37, pp. 129-137.

[7] J. M. Bvochora, J. D. Reed, J. S. Read, R. Zvauya, "Effect of fermentation processes on proanthocyanidins in sorghum during preparation of Mahewu, a non-alcoholic beverage," Process Biochem, 1999, vol. 35, pp. 21-25.

[8] L. Munck, "New milling technologies and products: Whole plant utilization by milling and separation of the botanical and chemical components," In: Dendy, D.A.V. (Ed.), Sorghum and Millets: Chemistry and Technology, American Association of Cereal Chemists, St. Paul, MN, USA, 1995, pp. 223-281.

[9] M. Ovando-Martinez, S. G. Sáyago-Ayerdi, E. Agama-Acevedo, I. Goñi, L. A. Bello -Pérez, "Unripe banana flour as an ingredient to increase the indigestible carbohydrates of pasta. Food Chemistry," 2009, vol.113, pp. 121-126.

[10] Chandler S. The nutritional value of bananas. In Gowen SR (ed.) Bananas and plantains. Chapman and Hall, London, 1995, pp. 7489.

[11] R. V. Mota, F. M. Lajolo, C. Ciacco, B. R. Cordenunsi, "Composition and functional properties of banana flour from different varieties," Starch/Sta"rke, 2000, vol. 52, pp. 63-68.

[12] N. Faisant, A. Buléon, P. Colonna, C. Molis, S. Lartigue, J. P. Galmiche, "Digestion of raw banana starch in the small intestine of healthy humans: structural features of resistant starch," British Journal of Nutrition, 1995, vol. 73, pp. 111-123.

[13] H. N. Englyst, S. M. Kingman, J. H. Cummings, "Classification and measurement of nutritionally important starch fractions," European Journal of Clinical Nutrition, 1992, vol. 46, pp. 33-50.

[14] CSIRO Division of Human Nutrition, "Dietary Fibre, Non-Starch Polysaccharides and Resistant Starch - A Review," Food Australia, 1996. 
[15] Silke Hylla, Andrea Gostner, Gerda Dusel, Horst Anger, Hans-P Bartram, Stefan U Christl, Heinrich Kasper, and Wolfgang Scheppach, "Effects of resistant starch on the colon in healthy volunteers: possible implications for cancer prevention," Am J Clin Nutr, 1998, vol. 67, pp. 136-142.

[16] K. R Silvester, H. N. Englyst, J. H. Cummings, "Ileal recovery of starch from whole diets containing resistant starch measured in vitro and fermentation of ileal effluent," Am. J. Clin. Nutr, 1995, vol. 62, pp. 403-411.

[17] A. Garc1'a-Alonso, A. Jimenez-Escrig, N. Mart1'n Carro' n, L. Bravo, F. Saura- Calixto, "Assessment of some parameters involved in the gelatinization and retrogration of starch," Food Chemistry, 1999, vol. 66, pp. 181-187.

[18] M. Kabir, M., J. M. Oppert, H. Vidal, F. Bruzzo, C. Fiquent, P. Wursch, "Four-week low-glycemic index breakfast with a modest amount of soluble fibre in type 2 diabetic men," Metabolism, 2002, vol. 51, pp. 819-826.

[19] P. Yue \& S. Waring S, "Functionality of resistant starch in food applications," Food Australia, 1998, vol. 50 , pp. 615 - 621.

[20] H. E. Martinez-Flores, Y. K. Chang, F. M. Bustos, F. S. Sinencio, "Extrusion-cooking of cassava starch with different fiber sources: effect of fibers on expansion and physicochemical properties," Adv Extrusions, 1999, 271-278.

[21] R. G. Hernández-Nava, J. Berrios, J. Pan, P. Osorio-Díaz, L. A. Bello-Pérez, "Development and characterization of spaghetti with high resistant starch content supplemented with banana starch," Food Science and Technology International, 2009, vol. 15, pp. 73-78.

[22] Maribel Ovando-Martinez, Sonia Sáyago-Ayerdi, Edith Agama-Acevedo, Isabel Goñi, A. Luis, Bello-Pérez, "Unripe banana flour as an ingredient to increase the undigestible carbohydrates of pasta," 2008.

[23] Abd Elmoneim O. Elkhalifa, Abdullahi H. El-Tinay, "Effect of cysteine on bakery products from wheat-sorghum blends," Food Chemistry, 2002, vol. 77, pp. 133-137.

[24] AACC. Approved Methods of the American Association of Cereal Chemists. American Association of Cereal Chemists. 10th ed. The Association INC. St., Paul, Minnesota, USA, 2000.

[25] C. Handa, S. Goomer, A. Siddhu, "Physicochemical properties and sensory evaluation of fructoligosaccharide enriched cookies," J. Food Sci Technol., 2011, vol. 49 (2), pp. 192-199.

[26] J. A. Awan, Salim-ur-Rehman, E. Ullah, M. I. Siddique, T. Aziz, "Nutrition of wheat flour in Islamic perspective," JAPS, 1991, vol.1, pp. 1-7.

[27] L. C. Doescher, R. C. Hoseney, G. A. Milliken, "Effects of flour components and dough ingredients on starch gelatinization," Cereal Chem., 1987, vol. 60, pp. 58-61.

[28] C. C. Tsen, "Regular and protein fortified biscuits from the composite flours," Cereal Foods World, 1976, vol. 21, pp. 633-640.

[29] H. Y. L. Kim, H. Yeom, H. S. Lim, S. T. Lim, "Replacement of shortening in yellow layer cakes by corn dextrins," Cereal Chem, 2001, vol. 78, pp. 267-271. 